\title{
Practical Reuse of Activated Carbon in the Exhaust Facility of Semiconductor Production Factory with Supercritical Carbon Dioxide Regeneration
}

\author{
Yasuyuki ITO ${ }^{1,2 *}$, Ikuo UshikI ${ }^{3}$, Yoshiyuki SATO ${ }^{1,4}$, and Hiroshi InOMATA ${ }^{1}$ \\ ${ }^{1}$ Department of Chemical Engineering, Graduate School of Engineering, Tohoku University, Aramaki Aza Aoba, 6-6-11, Aoba-Ku, \\ Sendai, Miyagi 980-8579, Japan \\ ${ }^{2}$ Technical Research Laboratory, Daidan Co., Ltd., 390 Kitanagai, Miyoshimachi, Irumagun, Saitama 354-0044, Japan \\ ${ }^{3}$ Department of Chemical Engineering, Graduate School of Engineering, Hiroshima University, Kagamiyama, 1-4-1, Higashi- \\ Hiroshima, Hiroshima 739-8527, Japan \\ ${ }^{4}$ Department of Environment and Energy, Faculty of Engineering, Tohoku Institute of Technology, 35-1 Yagiyama, Kasumicho, \\ Taihaku-Ku, Sendai, Miyagi, 982-8577, Japan
}

\begin{abstract}
An possible reason why the activated carbon used in the exhaust facility of real semiconductor production factory could not be regenerated by $\mathrm{scCO}_{2}$ regeneration was estimated to be attributable to its high boiling point adsorbates which showed a peak in TGA (Thermogravimetric analysis) curve at $400-900^{\circ} \mathrm{C}$. This study was conducted to experimentally verify the above insight by using TGA analysis and $\mathrm{ScCO}_{2}$ regeneration for the real samples with different loads from the factory. The experimental results showed that high boiling point ratio defined by TGA analysis was less than $4.0 \%$ in case of the heating treatment temperature of 200 ${ }^{\circ} \mathrm{C}$ in the exhasut facility of real semiconductor production factory. This result suggested regeneration rate of the activated carbon was higher than $80 \%$. Our $\mathrm{scCO}_{2}$ regeneration process can achieve high efficiency as a practical application.
\end{abstract}

\section{Introduction}

Activated carbon has been widely used to prevent emissions of volatile organic compounds (VOCs) in industrial processes because of its high adsorption ability. Regeneration of used activated carbon is strongly demanded from viewpoint of reduction of industrial wastes for SDGs (sustainable development goals). Supercritical carbon dioxides $\left(\mathrm{scCO}_{2}\right)$ is a promising solvent for the regeneration of activated carbon because of its high diffusivity into the microstructure and ability to operate at a moderate temperature (critical point:304 K) resulting in less damage to the microstructure of activated carbon (Tamura et al., 2005).

We have studied the $\mathrm{scCO}_{2}$ regeneration for activated carbon used in exhaust facilities of a real semiconductor production factories, which suggested that long-term used activated carbon could not be regenerated (Ito et al., 2019a). Thermogravimetric analysis (TGA) showed that $\mathrm{scCO}_{2}$ could remove low boiling point adsorbates (100$400^{\circ} \mathrm{C}$ ) such as VOCs but could not remove high boiling point adsorbates $\left(400-900^{\circ} \mathrm{C}\right)$. The high boiling point ratio defined as the proportion of high boiling point adsorbates showed that regeneration rates of $90 \%$ and $80 \%$ were achieved at high boiling point ratios of $2.0 \%$ and $4.0 \%$, respectively. Table 1 summarizes the high boiling point ratio used in the exhaust facility with operational heating temperatures of $250-400^{\circ} \mathrm{C}$ (Ito et al., 2019a). The high boiling point adsorbates were possibility caused by propylene glycol monomethyl ether (PGME) and propylene glycol monomethyl ether acetate (PGMEA) as main VOC components at practical semiconductor production processes. The experimental results showed that activated carbon loaded with PGME or PGMEA was influenced by heating treatment, and high boiling point adsorbates were observed in the case of heating temperature of higher than $250^{\circ} \mathrm{C}$, which suggested that heating temperature of $200^{\circ} \mathrm{C}$ formation of prevented high boiling point adsorbates (Ito et al., 2019b).

We have operated the exhaust facility of the real semiconductor production factory in case of heating treatment temperatures of $200-300^{\circ} \mathrm{C}$ and $200^{\circ} \mathrm{C}$ effective preventing formation of high boiling point adsorbates for the efficiency $\mathrm{scCO}_{2}$ regeneration process. In this work, the high boiling point ratio of the activated carbon used in the exhaust facility of the real semiconductor production factory in case of heating treatment temperatures of 200$300^{\circ} \mathrm{C}$ and $200^{\circ} \mathrm{C}$ were studied. 
Table 1. Activated carbon used in the exhaust facility with heating temperatures of $250-400^{\circ} \mathrm{C}$ (Ito et al., 2019a)

\begin{tabular}{|c|c|c|c|}
\hline & $\begin{array}{c}\text { Heating } \\
\text { Temperature } \\
{\left[{ }^{\circ} \mathrm{C}\right]}\end{array}$ & $\begin{array}{l}\text { Duration } \\
\text { time } \\
\text { [Month] }\end{array}$ & $\begin{array}{c}\text { High boiling } \\
\text { point ratio } \\
{[\%]}\end{array}$ \\
\hline \multirow{8}{*}{ Lot. A } & \multirow{8}{*}{$250-400$} & 3 & 2.7 \\
\hline & & 4 & 2.4 \\
\hline & & 5 & 2.9 \\
\hline & & 6 & 2.8 \\
\hline & & 7 & 3.6 \\
\hline & & 8 & 3.1 \\
\hline & & 9 & 4.0 \\
\hline & & 10 & 5.2 \\
\hline \multirow{5}{*}{ Lot. B } & \multirow{5}{*}{$250-400$} & 1 & 2.7 \\
\hline & & 3 & 2.9 \\
\hline & & 4 & 3.3 \\
\hline & & 5 & 3.9 \\
\hline & & 7 & 4.2 \\
\hline \multirow{4}{*}{ Lot. C } & \multirow{4}{*}{$250-400$} & 2 & 3.3 \\
\hline & & 3 & 3.3 \\
\hline & & 4 & 4.7 \\
\hline & & 5 & 4.7 \\
\hline \multirow{6}{*}{ Lot. D } & \multirow{6}{*}{$250-400$} & 1 & 1.8 \\
\hline & & 2 & 3.1 \\
\hline & & 3 & 3.6 \\
\hline & & 4 & 4.8 \\
\hline & & 5 & 6.1 \\
\hline & & 6 & 6.9 \\
\hline
\end{tabular}

\section{Experiment}

\subsection{Materials}

Table 2. Activated carbon used in the exhaust facility with heating temperatures of $200-300{ }^{\circ} \mathrm{C}$ (Lot. E), $200^{\circ} \mathrm{C}$ (Lot. F)

\begin{tabular}{cccc}
\hline & $\begin{array}{c}\text { Heating } \\
\text { Temperature } \\
{\left[{ }^{\circ} \mathrm{C}\right]}\end{array}$ & $\begin{array}{c}\text { Duration } \\
\text { time } \\
{[\text { Month }]}\end{array}$ & $\begin{array}{c}\text { High boiling } \\
\text { point ratio } \\
{[\%]}\end{array}$ \\
\hline \multirow{3}{*}{ Lot. E } & & 3 & 2.0 \\
& & 5 & 2.8 \\
& $200-300$ & 7 & 3.5 \\
& & 9 & 4.1 \\
\hline \multirow{3}{*}{ Lot. F } & \multirow{3}{*}{200} & 5 & 2.4 \\
& & 7 & 2.3 \\
& & 9 & 2.8 \\
& & 11 & 3.3 \\
& & 13 & 3.5 \\
& & 16 & 3.9 \\
\hline
\end{tabular}

Activated carbon samples in this study are summarized in Table 2. Specific surface area of the activated carbon is $1388 \mathrm{~m}^{2} / \mathrm{g}$ on new state was determined by the $t$ method (de Boer et al., 1965) using a nitrogen adsorption measurement apparatus (Belsorp mini, MicrotracBEL CO., Japan). These samples are continuously used in the exhaust facility of the real semiconductor production factory. Figure 1 shows schematic diagram of the exhaust facility consisted of adsorption tower (activated carbon on new state: ca. $1000 \mathrm{~kg}$ ) and desorption tower. Adsorption tower removed hazardous substance such as VOCs, including, PGME and PGMEA, then activated carbon in the desorption tower was continuously regenerated by heating treatment. Heating treatment temperature of the desorption tower was controlled at temperatures of 200$300^{\circ} \mathrm{C}$ (Lot. E) and $200^{\circ} \mathrm{C} \mathrm{(Lot.} \mathrm{F).}$

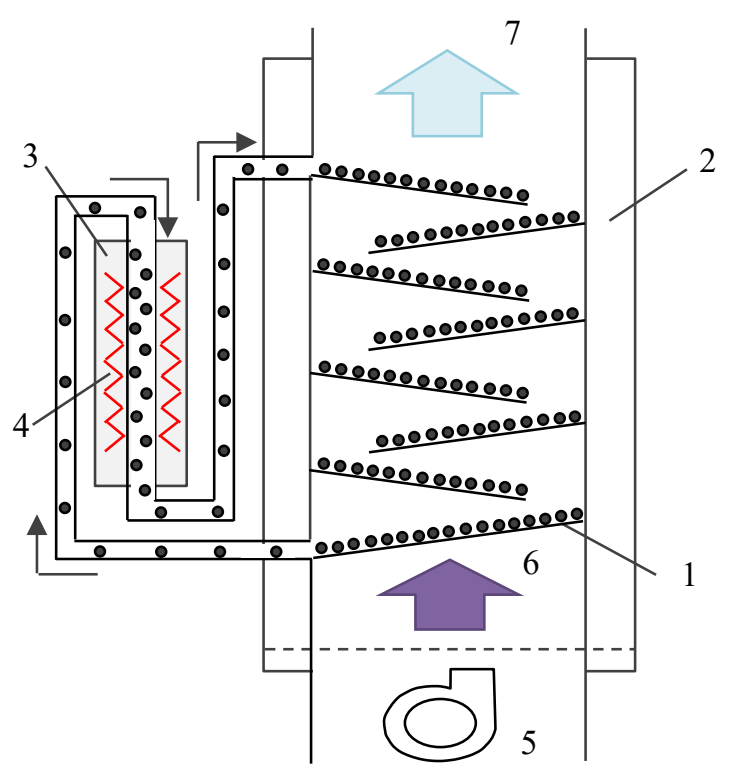

1. Activated carbon, 2. Adsorption tower, 3. Desorption tower, 4. Electric heater, 5. Exhaust fan, 6. Polluted exhaust gas, 7. Purified exhaust gas

Figure 1. The schematic diagram of the exhaust facility of semiconductor production factory

\subsection{Analysis}

The amounts of high boiling adsorbate in the activated carbon were determined by TGA-DTA (EVO, Rigaku CO., Japan). TGA conditions are mass of sample (activated carbon): $20 \mathrm{mg}$, heating temperature: 25$1000^{\circ} \mathrm{C}$, temperature rate: $10^{\circ} \mathrm{C} / \mathrm{min}$, Atmosphere: $\mathrm{N}_{2}$ (99.9\%) and $\mathrm{N}_{2}$ flow: $500 \mathrm{ml} / \mathrm{min}$. Figure 2 shows TGA result of the used activated carbon in the exhaust facility (Lot .F, used duration time : 16 month). DTG (Derivative TG) curve shows bimodal shapes corresponded to low boiling point adsorbates $\left(100-400^{\circ} \mathrm{C}\right)$ and high boiling 
point adsorbates $\left(400-900^{\circ} \mathrm{C}\right)$. The high boiling point ratio was defined by equation (1) (Ito et al., 2019a).

High boiling point ratio $[\%]=\frac{W_{400}-W_{900}}{W_{100}} \times 100$

where $W_{100}, W_{400}$ and $W_{900}$ are TG value (mass of activated carbon) at $100^{\circ} \mathrm{C}, 400^{\circ} \mathrm{C}$ and $900^{\circ} \mathrm{C}$, respectively.

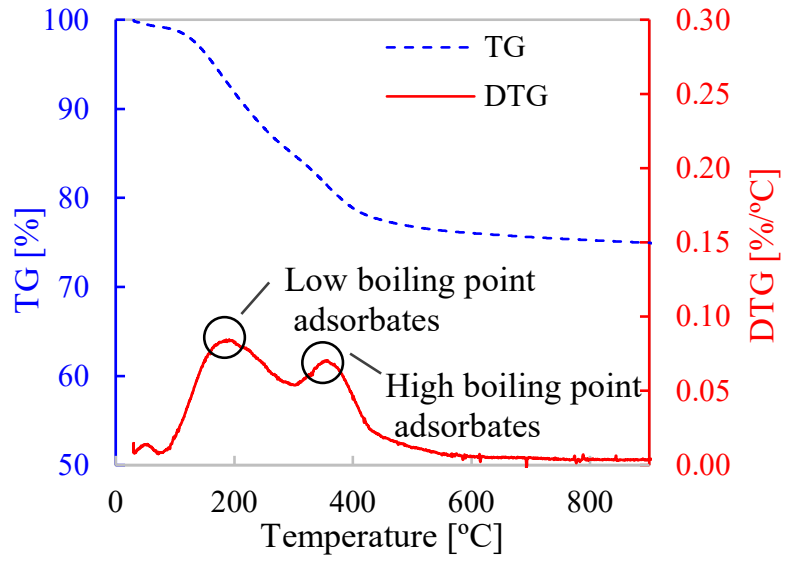

Figure 2. TGA of used the activated carbon in the exhaust facility of semiconductor production factory (used duration time : 16 month)

\section{Result and Discussion}

Figure 3 shows relationship between high boiling point ratio and used duration time at heating temperatures of $250-400^{\circ} \mathrm{C}$ in the exhaust facility of the real semiconductor production factory. The high boiling point ratio was linearly and dramatically increased with passage of time. 4 types of used activated carbon (Lot. A-D) were each of different semiconductor manufacturing processes of loads (Ito et al., 2019a).

Figure 4 shows relationship between high boiling point ratio and used duration time in cases of heating temperatures of $200-300^{\circ} \mathrm{C}$ (Lot. E) and $200^{\circ} \mathrm{C}$ (Lot. F) in the exhaust facility of the real semiconductor production factory. Our previous works showed that high boiling point adsorbates were possibility caused by PGME and PGMEA with heating temperature of higher than $250^{\circ} \mathrm{C}$ in a laboratory-scale (Ito et al., 2019b). The activated carbon with heating treatment of temperature of $200^{\circ} \mathrm{C}$ for $63 \mathrm{~h}$ was not observed high boiling point adsorbates, suggesting that the treatment temperature of $200^{\circ} \mathrm{C}$ was effective for preventing formation of the high boiling point adsorbates. The activated carbon of Lot. E was heated mainly temperature of $200^{\circ} \mathrm{C}$ additionally partial heating temperatures of $250^{\circ} \mathrm{C}$ and $300^{\circ} \mathrm{C}$ by means of practical operation. It was supposed that high boiling point ratios of Lot. E were relatively lower than Lot. A-E because of decreasing heating temperature of desorption tower. The activated carbon of Lot. F was heated temperature of $200^{\circ} \mathrm{C}$. The high boiling point ratio of Lot. F (used duration time: 5-16 month) was less than 4.0\%, which suggested higher regeneration rate of than $80 \%$.

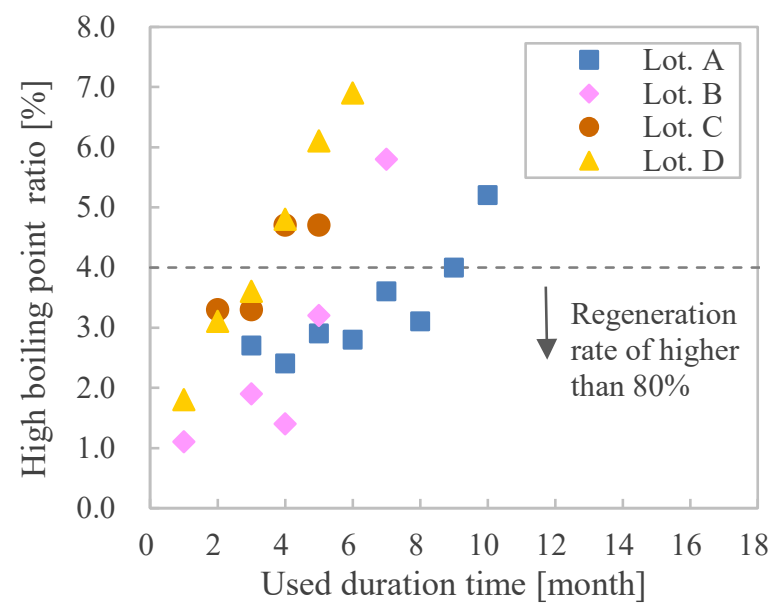

Figure 3. Relationship between high boiling point ratio and used duration time (heating temperatures of $250-400^{\circ} \mathrm{C}$ )

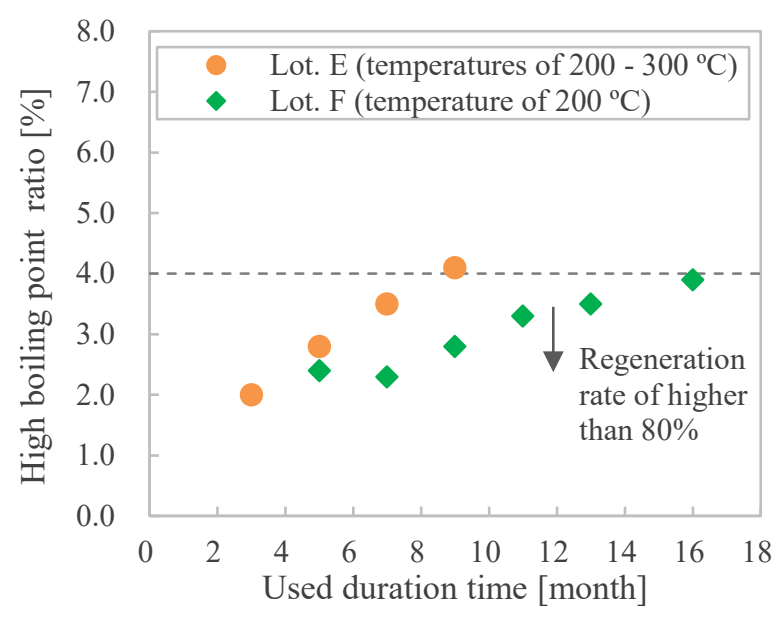

Figure 4. Relationship between high boiling point ratio and used duration time (Lot. E (heating temperatures of $200-300^{\circ} \mathrm{C}$ ), Lot. $\mathrm{F}$ (heating temperature of $\left.200^{\circ} \mathrm{C}\right)$ )

\section{Conclusion}

The $\mathrm{scCO}_{2}$ regeneration of activated carbon used in exhaust facility of the real semiconductor production factory was studied. The heating temperature of $200^{\circ} \mathrm{C}$ in the exhaust facility of desorption tower was effective for preventing formation of high boiling point adsorbates similarly laboratory-scale results. The $\mathrm{scCO}_{2}$ regeneration activated carbon was high boiling point ratio of less than $4.0 \%$, suggesting higher regeneration rate than $80 \%$. Our $\mathrm{scCO}_{2}$ regeneration process could achieve high efficiency as a practical application. 


\section{References}

Boer, J. H.,, B. G. Linsen, T. van der Plas, G. J. Zondervan, Journal of Catalysis, 4, 649 (1965)

Ito, Y., I. Ushiki, Y. Sato and H. Inomata; "Supercritical carbon dioxide regeneration of activated carbon for exhaust process," Kagaku Kogaku Ronbunshu, 45, 29-34 (2019a)

Ito, Y., I. Ushiki, Y. Sato and H. Inomata; "Influence of heat treatment in exhaust treatment process on activated carbon regeneration using supercritical carbon dioxide," Kagaku Kogaku Ronbunshu, 45, 133-139 (2019b)

Tamura, K., S. Nakamura, Y. Sasaki, H. Inomata and M. Kikuchi; "A Study on Regeneration of Chemical Filters Polluted by Volatile Organic Compound," Proceeding of The Society of Heating, Air-Conditioning and Sanitary Engineers of Japan, E-62 (2005) 